\begin{tabular}{ll}
\hline \hline MINING AND METALLURGY INSTITUTE BOR & ISSN: 2334-8836 (Štampano izdanje) \\
UDK: 622 & ISSN: 2406-1395 (Online) \\
\hline \hline
\end{tabular}

\author{
Vladimir M. Petrovic', Mirko Borisov ${ }^{* *}$, Dragan Zlatanovic ${ }^{* * *}$, \\ Lidija Djurdjevac Ignjatovic '**** $^{*}$
}

\title{
VERTICAL ACCURACY OF DATA ON THE TOPOGRAPHIC MAPS AND THEIR APPLICATION IN MINING*
}

\begin{abstract}
The paper describes some experiences and the methodology used for evaluation the vertical accuracy of data on the official (state) topographic maps. The vertical accuracy is an important element of quality $3 D$ representation on the topographic maps in digital, as well as in analoguos forms. A comparative way of testing is usually applied for determining the vertical accuracy, namely the comparison of the measured values of topographic maps with "true" or "conditionally true" values (numeric data of the geodetic and height points). This method gives a direct accuracy assessment of the printed maps and 3D terrain models, especially when used in industries such as mining. To a large extent, the vertical accuracy of data and geomorphology (geographic) fidelity relief on the topographic maps is not always sufficient quality. The type of survey and how the matter affects the quality, or the geodetic control points are drawn precisely, where the accuracy of the contour lines is lower. However, the application of a new technology is changes the $3 D$ visualization of terrain, thus increasing the vertical accuracy of data.
\end{abstract}

Keywords: topographic map, 3D data model, vertical accuracy, application, mining

\section{INTRODUCTION}

Using geospatial information within the decision making process in the mining, armed forces, hydrology, especially after the appearance of floods and wide application in the state administration. At the same time, the importance of knowing its quality is also increasing; if decisions are based on a digital based technology. According to the ISO 19157:2013, the quality of geographical information is described in a quantitative way with five elements: completeness, logical consistency, positional accura-

\footnotetext{
* University of Belgrade, Institute of Chemistry, Technology and Metallurgy, Department for Ecology and Technoeconomics, Njegoševa 12, 11000 Belgrade, Republic of Serbia; e-mail:vladimirpetrovic.gis@gmail.com

** University of Novi Sad, Faculty of Technical Sciences, Trg Dositej Obradović 6, 21000 Novi Sad, Republic of Serbia; e-mail:mirkoborisov@gmail.com

*** Innovation Center, Faculty of Mechanical Engineering University of Belgrade, Kraljice Marije 16, 11000 Belgrade, Republic of Serbia, e-mail:dr.dragan.zlatanovic@gmail.com

***** Mining and Metallurgy Institute Bor, 19210 Bor, Zeleni bulevar 35, e-mail: lidijadj.ignjatovic@irmbor.co.rs

****** This work was supported by the Ministry of Education, Science and Technological Development, Government of the Republic of Serbia (Project No. OI 176018), and the result of the Project No. TR 33021 "Research and Monitoring the Changes of the Stress Strain State in the Rock Mass "InSitu" around the Underground Rooms with Development of Models with Special Reference to the Tunnel of the Krivelj River and Pit Bor", funded by the Ministry of Education, Science and Technological Development of the Republic of Serbia
} 
cy, temporal accuracy and thematic accuracy. The term positional accuracy means the compliance of a point position that belongs to some topographic model belongs to its true position in space. The positional accuracy may be a horizontal and a vertical accuracy, (Perdue, 2013).

This article focuses on the official topographic maps at a scale of 1:25 000 (TM25), topographic maps at a scale of 1:50 000 (TM50) and topographic maps at a scale of 1:100 000 (TM100), in the classic (older) and digital (newer) forms. One of the main goals in this article is to determine the vertical accuracy of geodata and for that a comparative method of testing is usually applied, with the comparison of measured values of height displaying a field with the "real" or "conditional exact" values. This article also focuses on digital terrain modeling and 3D data models. These models were created with the conversion from an analog form of topographic maps to a digital, while considering various aspects of digitization the cartographic sources.

\section{INTERNATIONAL STANDARDS FOR VERTICAL ACCURACY EVALUATION}

The international standards define the basic principles and procedures for vertical accuracy assessments and evaluations. There are no particular measures of accuracy, or statistics of calculations and quality reports such as the standard deviation or meansquare error. It is a matter of the ISO standards user that defines those things as they wish according to their objectives and positional accuracy reports. The same goes for the "industrial" or "de facto" standards at the international level. Just at a national level, there are standards, which, in detail, deal with this matter, although there are only few such countries, (Iliffe, et al., 2013).

Two of America's national standards have a strong influence on the standardization in this area: the United States National Map Accuracy Standards (NMAS) from
1947., and the National Standard for Spatial Data Accuracy (NSSDA) from 1998. The first one is related to assessments of mainly analogous maps (sometimes of digital maps too) and is not quite appropriate for using in conditions nowadays, while the second one is modern and usable nowadays; it is related to all digital spatial data (in a raster as well as in a vector form). To those standards one has to attach the very detailed and overall excellent elaborated standard STANAG 2215 - Evaluation of Land Maps, Aeronautical Charts and Digital Topographic Data and maps, (Radojčić, et al., 2011).

The positional accuracy of data sets with $3 \mathrm{D}$ coordinates is determined by combining the results of horizontal accuracy assessments (accuracy related to the horizontal geodetic datum, i.e. 2D coordinates) and vertical accuracy assessments (accuracy related to the vertical geodetic datum, i.e. 1D coordinates), (Aguilar, et al., 2010). The NSSDA uses the root-mean-square error (RMSE) to estimate the positional accuracy. The RMSE is the square root of the average of the set of squared differences between the dataset coordinate values and the reference coordinate values for identical points. The positional accuracy values are reported in ground distances (metric units or feet). This allows users to directly compare datasets of differing scales or resolutions. The accuracy is reported with a $95 \%$ certainty level. For example, the vertical accuracy lets:

$$
R M S E_{h}=\sqrt{\frac{1}{n} \sum_{1}^{n} d h^{2}}
$$

where $d h$ are the differences between the measured and reference vertical coordinates of points (control heights).

Furthermore, the standard (ISO, 2013) defines the absolute and relative (point-topoint) accuracy. Under the absolute accuracy standard it can assume the uncertainty in the $3 \mathrm{D}$ position of a point with respect to the WGS84 reference system, combined with EGM96 geoid model (Radojčić, et al., 2011). The absolute vertical accuracy is 
uncertain in terms of the height of a point with respect to the vertical datum. It is expressed as a linear error with a $90 \%$ certainty level. The relative vertical accuracy is uncertain in terms of the height difference between two points; it is expressed as a circle of error, i.e. a linear error with a $90 \%$ certainty level.

In the vertical accuracy evaluation procedure, the first step is to calculate the height differences between the measured and reference height $\delta H_{i}$, the next step is to calculate the differences from the mean value of all differences $\overline{\delta H}$ and to calculate the linear standard deviation, (Radojčić, et al., 2011):

$$
\sigma_{L}=\sqrt{\frac{\sum\left(\delta H_{i}-\delta \bar{H}\right)^{2}}{n-1}}
$$

Next, the tests for blunders and systematic errors are performed. Finally, one has to evaluate the linear error with a $90 \%$ certainty level, in the English language it is traditionally noted as LMAS (Linear Map Accuracy Standard). If is not significantly differing from the zero value, LMAS is calculated as:

$$
L M A S=1,645 \cdot \sigma_{m},
$$

All topographic-cartographic products are divided in five classes (Table 1) by the value of the LMAS, (Radojčić, et al., 2011).

Table 1 The topographic-cartographic products classification by vertical accuracy

\begin{tabular}{|c|c|c|c|c|c|}
\hline \multirow{2}{*}{ Class } & \multicolumn{5}{|c|}{ Resolution or the map scale } \\
\cline { 2 - 6 } & $\mathbf{1 : 2 5} \mathbf{0 0 0}$ & $\mathbf{1 : 5 0 ~ 0 0 0}$ & $\mathbf{1 : 1 0 0 ~ 0 0 0}$ & $\mathbf{1 : 2 0 0 ~ 0 0 0}$ & $\mathbf{1 : 2 5 0 ~ 0 0 0}$ \\
\hline 0 & $2.5 \mathrm{~m}$ & $5 \mathrm{~m}$ & $10 \mathrm{~m}$ & $20 \mathrm{~m}$ & $25 \mathrm{~m}$ \\
\hline 1 & $5 \mathrm{~m}$ & $10 \mathrm{~m}$ & $20 \mathrm{~m}$ & $40 \mathrm{~m}$ & $50 \mathrm{~m}$ \\
\hline 2 & $10 \mathrm{~m}$ & $20 \mathrm{~m}$ & $40 \mathrm{~m}$ & $80 \mathrm{~m}$ & $100 \mathrm{~m}$ \\
\hline 3 & \multicolumn{6}{|c|}{ Poorer than class 2} \\
\hline 4 & \multicolumn{6}{|c|}{ Not determined } \\
\hline
\end{tabular}

For the vertical accuracy evaluation, the STANAG 2215 demands at least 167 check points per data set, just like for the horizontal accuracy evaluation. However, in this case, the samples have to be representative not only in a planar sense, but in a vertical sense too. This means that, within the data set, there have to be check points with different heights, especially points with extreme heights.

\section{SERBIAN EXPERIENCES IN ANALYSIS FOR VERTICAL ACCURACY OF DATA}

The Military Geographical Institute (MGI) created a system of topographic maps whose main content is based on photogrammetric land survey and the periodic cycles of revision and amendments after that time period. On this basis, the MGI obtained geographical maps at the different scales and contents. They were created using the system of derived maps and were represented in the conformal (Gauss-Kruger) map projection, with the Greenwich meridian as the default. The same or similar cartographic-editorial decisions are applied. In other words, all maps are created in a single geodetic and cartographic system, which considerably facilitates their application.

In this article, the data quality of the relief on the topographic maps includes both the vertical accuracy and the geographic fidelity (data quality). For the analysis of the quality of the data, topographic maps at the scales TM25, TM50 and TM100 have been considered. Using 3D geospatial information within the decision making process in the mining (Figure 1) and wide application in the state administration. 

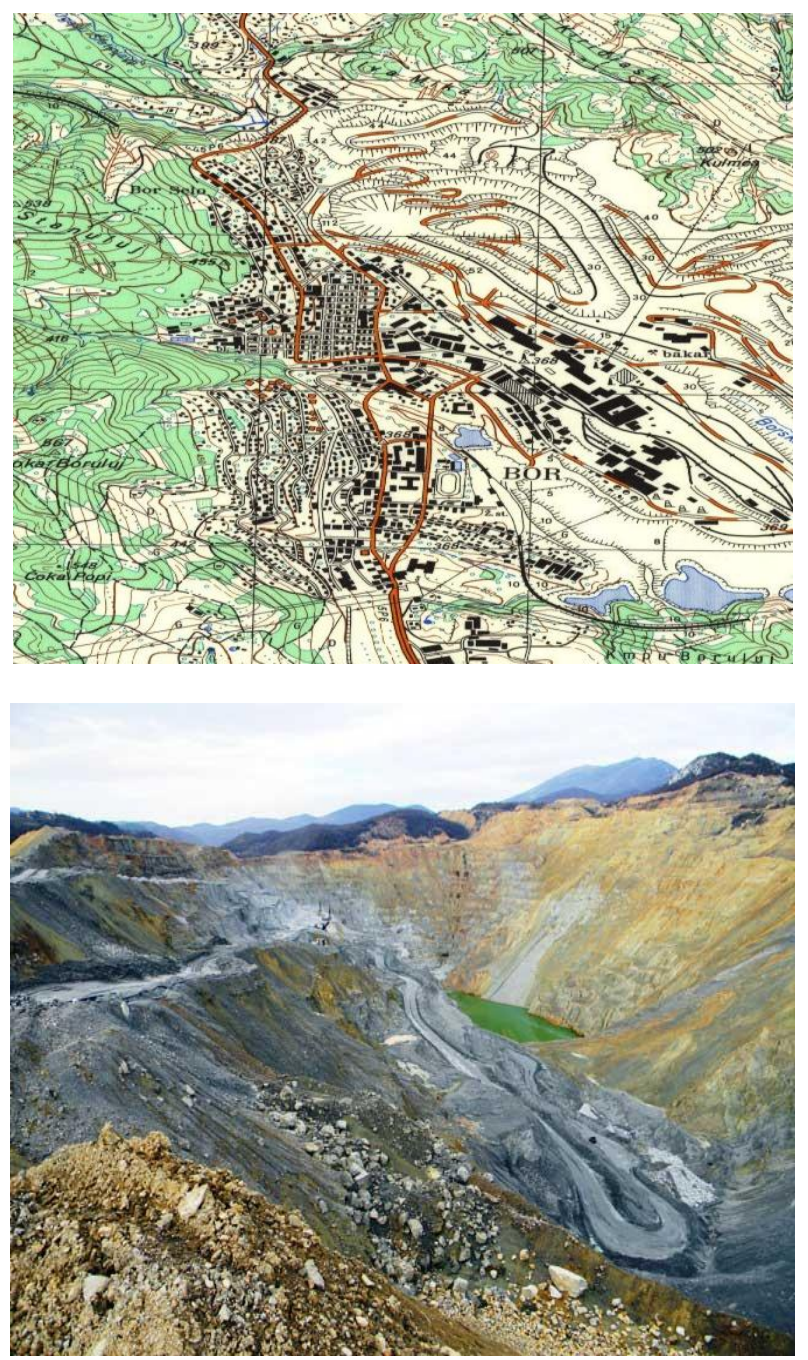

Figure 1 Mining Basin Bor - Veliki Krivelj (URL 1) (http://rtb.rs/rtb-bor-doo/rudnik-bakra-bor/rudnik-bakra-veliki-krivelj/)

\section{THE TRADITIONAL TOPOGRAPHIC}

\section{MAPS}

The vertical accuracy of topographic maps depends on the precision of representation the relief and scale, (Frančula, $2003)$, i.e. the accuracy of contour lines as the main way of the relief representation and the accuracy of numerically marked elevation points (levels). The mean square

errors of positions the contour lines, which determine the vertical accuracy, are commonly used as an elevation indicator of the accuracy of topographic maps, as well as the mean square errors of the heights of points in relation to the nearest geodetic control points (Table 2). 
Table 2 The comparison of vertical accuracy of TM25, TM50 and TM100

\begin{tabular}{|c|c|c|c|}
\hline \multirow{2}{*}{$\begin{array}{c}\text { The vertical accuracy } \\
\text { Criterion }\end{array}$} & \multicolumn{3}{|c|}{ The mean square error $(\mathrm{m})$} \\
\hline & TM25 & TM50 & TM100 \\
\hline $\begin{array}{l}\text { The vertical accuracy } \\
\text { of detailed points }\end{array}$ & $\sigma_{\mathrm{h}}= \pm 2.1$ & $\sigma_{\mathrm{h}}= \pm 2.7$ & $\sigma_{\mathrm{h}}= \pm 3.3$ \\
\hline $\begin{array}{l}\text { The vertical accuracy } \\
\text { of detailed points by } \\
\text { Koppe }\end{array}$ & $\sigma_{\mathrm{h}}= \pm(1.4+4.1 \operatorname{tg} \alpha)$ & $\sigma_{\mathrm{h}}= \pm(1.3+14 \operatorname{tg} \alpha)$ & $\sigma_{\mathrm{h}}= \pm(1.1+31 \operatorname{tg} \alpha)$ \\
\hline
\end{tabular}

Formulas and many expressions used as indicators of the relief quality represented by contour lines do not give a precisely and easily understandable picture of deviation thecontour lines and their actual position. The accuracy of the elevation points of the contour lines is determined by many complex procedures. One of the commonly used equations is defined by Koppe:

$$
\sigma_{h}= \pm(A+B \operatorname{tg} \alpha)
$$

where $\alpha$ is the slope of terrain, and $A$ and $B$ are coefficients which are determined depending on the scale and type of the cartographic material (paper map or reproduction original).

The geomorphology (geographic) fidelity of maps includes the relief content and time determinations, namely data fidelity of topographic content. It is impossible to find a mathematical expression for geographic fidelity. Only the number of errors in relation to the total number of data can be de termined, such as names or signs in a single sheet of a topographic map. Obsolete, outdated, and thus, defective or incorrect content decreases the quality and usefulness of a topographic map, since they do not show exact reality as it is, but the condition as it was. The geomorphological fidelity relief on the topographic maps depends on the scale of mapping and the time covered by the data height on the map; it also depends on the overall quality of the map. From the point of visualization and data density on a topographic map, an important factor is the factor of loaded content that is directly related to the other two factors: the geographic fidelity and the accuracy of vertical display. Criteria displayed and the density of data on topographic maps is:

- Evaluating and comparing the structure of content: geodetic points, peaks, contour lines, course lines, ridge lines (Figure 2); and

- The analysis of the density and degree of generalization elements of map.

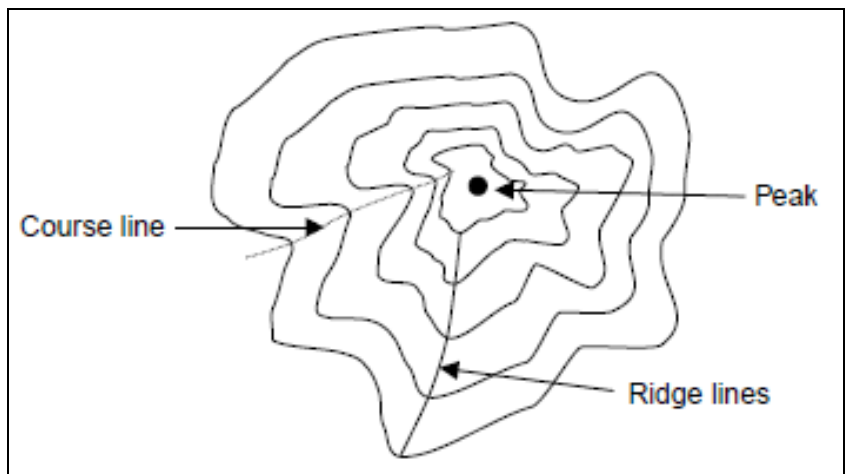

Figure 2 Display the relief on maps by lines and check points (Li, Z., Zhu, Q., Gold, C., 2005.) 
Geodetic control points have particular relevance to the topographic maps at larger scale. That is the reason that the structure of geodetic control points selected had to be identical to TM25, TM50 and TM100.
A comparative review of the structure of the geodetic control points at these maps and the scope of mapped content of geodetic base analyzed a sample of 16 sheets TM25 covering geographical territory of Serbia (Table 3).

Table 3 Data on geodetic points

\begin{tabular}{|c|l|c|c|c|}
\hline \multicolumn{2}{|c|}{ Geodetic points } & \multicolumn{3}{c|}{ The map scale } \\
\cline { 2 - 4 } \multicolumn{2}{|l}{} & TM25 & TM50 & TM100 \\
\hline 1 & Trigonometric point & $\bullet$ & $\bullet$ & $\bullet$ \\
\hline 2 & Spot elevation with values in (m) & $\bullet$ & $\bullet$ & $\circ$ \\
\hline 3 & $\begin{array}{l}\text { Religious building as geodetic point (church, mosque, } \\
\text { synagogue, monastery) }\end{array}$ & $\bullet$ & $\bullet$ & $\bullet$ \\
\hline 4 & $\begin{array}{l}\text { Infrastructure facility such geodetic point (factory } \\
\text { chimney, telecommunication tower, weather station) }\end{array}$ & $\bullet$ & $\bullet$ & $\bullet$ \\
\hline 5 & Border post as a trigonometric point & $\bullet$ & $\bullet$ & $\circ$ \\
\hline 6 & Monument as a trigonometric point & $\bullet$ & $\bullet$ & $\bullet$ \\
\hline 7 & Saddle as spot elevation & $\bullet$ & $\bullet$ & $\bullet$ \\
\hline$\bullet$ displayed on TM & & & \\
\hline & not shown on TM & & & \\
\hline
\end{tabular}

Comparing the number of mapped points of geodetic base (trigonometry and elevation points) on the sheets TM25, TM50 and TM 100, produced the data shown in Table 4.

Table 4 Comparison of the number of mapped points of geodetic basis on the TM

\begin{tabular}{|l|c|c|c|}
\hline The map scale & Area in $\%$ & $\begin{array}{c}\text { Ratio of trigonometric } \\
\text { points in } \%\end{array}$ & $\begin{array}{c}\text { Ratio of spots } \\
\text { elevation in } \%\end{array}$ \\
\hline TK25 & 100 & 100 & 100 \\
\hline TK50 & 25 & 49 & 30 \\
\hline TK100 & 6 & 26 & 15 \\
\hline
\end{tabular}

Here, the average values are given, but it is important to note that different approach were applied to the generalization of trigonometry and elevation points from sheet to sheet of the maps. The range values of the generalization of trigonometry is from $100 \%$ to $26 \%$, while the range of the generalization of the elevation spots is from $100 \%$ to $15 \%$; that means that there were a lot of subjective approaches to the cartographic generalization.
A higher degree of generalization of the elevation was caused by generalization of the others, especially line elements of map. But even so, it should be noted that the number of mapped trigonometry and elevations decreases much slower than the surface on the topographic map showing the designated area.

The main difference in the relief representation on the TM50, compared to the TM25 and TM100, is in the primary equidistance. On the TM50 it is twice higher, 
being it is $20 \mathrm{~m}$. Keeping this in mind, it can be concluded that the TM25 can display details of the relief that are higher or lower than $2.5 \mathrm{~m}$, while on the TM50, details can display the relief higher or lower than $5 \mathrm{~m}$, using the intermediate contour lines. Even so, they show characteristic landforms, which are not present in the intermediate contours at 1/4 of equidistance (curl, vale, sinkholes).
The amount of details in the relief that can be displayed on the TM50 and TM100 is increased. As the TM50 equidistance is $20 \mathrm{~m}$, in the most favorable case (flat terrain) on the basis of experience, the height can be read with an accuracy of up to 1/10 of equidistance. Data on the relief and land forms of the TM25, TM50 and TM100 are given in Table 5.

Table 5 Data of relief and reliefforms on TM

\begin{tabular}{|c|l|c|c|c|}
\hline \multicolumn{2}{|c|}{ Relief } & \multicolumn{3}{c|}{ Map scale } \\
\cline { 3 - 5 } \multicolumn{2}{|l}{} & TK25 & TK50 & TK100 \\
\hline 1 & Basic contour line - index 10, 20 and 20 (40) m & $\bullet(10)$ & $\bullet(20)$ & $\bullet(20)$ \\
\hline 2 & Main contour line - index 50, 100 and 200 m & $\bullet(50)$ & $\bullet(100)$ & $\bullet(200)$ \\
\hline 3 & Intermediate line at 1/2 equidistance & $\bullet$ & $\bullet$ & $\bullet$ \\
\hline 4 & Intermediate line at 1/4 equidistance & $\bullet$ & $\bullet$ & $\bullet$ \\
\hline 5 & $\begin{array}{l}\text { In the field, visible landforms (curl, vale that can } \\
\text { display contour lines) - contour line third category }\end{array}$ & $\bullet$ & $\bullet$ & $\bullet$ \\
\hline 6 & Sinkholes in scale or as a conditional sign & $\bullet$ & $\bullet$ & $\bullet$ \\
\hline 7 & $\begin{array}{l}\text { Lonely rock that cannot be provided in the ratio } \\
\text { of map }\end{array}$ & $\bullet$ & $\bullet$ & $\circ$ \\
\hline 8 & $\begin{array}{l}\text { Ravines and gorges of natural distance from the } \\
\text { river bank }\end{array}$ & $\bullet$ & $\bullet$ & $\bullet$ \\
\hline 9 & Dents and terraces of banks flows in flat terrain & $\bullet$ & $\bullet$ & $\bullet$ \\
\hline 10 & Gully - gullies & $\bullet$ & $\bullet$ & $\bullet$ \\
\hline 11 & Karst sink- holes & $\bullet$ & $\bullet$ & $\circ$ \\
\hline 12 & Dry moat & $\bullet$ & $\bullet$ & $\circ$ \\
\hline 13 & Abyss & $\bullet$ & $\bullet$ & $\bullet$ \\
\hline 14 & Heaps of stone - a mound & $\bullet$ & $\bullet$ & $\bullet$ \\
\hline 15 & Cave with water or without water & $\bullet$ & $\circ$ \\
\hline
\end{tabular}

- displayed on TM

$\circ$ not shown on TM

When it comes to show the land forms, the nature of that element of content the topographic maps should be the least changeable, (Petrović, at al., 2016). However, in the relief area there is a variety of changes due to the human activities (reclamation, mining, etc.) and there are also the influence of natural forces (landslides, erosion, etc.). In addition, substantial changes are visible in a view of relief applying the specific methods of surveying and cartography (topographic and photogrammetric surveys, base height, generalization of field types, etc.). Also, the construction of open pits and tailings, power plants, and accumulation of lakes and a network of channels cause modifications of confluences and river flows.

\section{DIGITAL TOPOGRAPHIC MAPS}

The vertical accuracy of digital topographic maps depends on the process of analogous to digital conversion (Figure 3), 
and the methods of data georeferencing and processing (system of technical possibilities and human factor). Nevertheless, the general quality depends on the positional and height accuracy of the topographic content, and data updating.
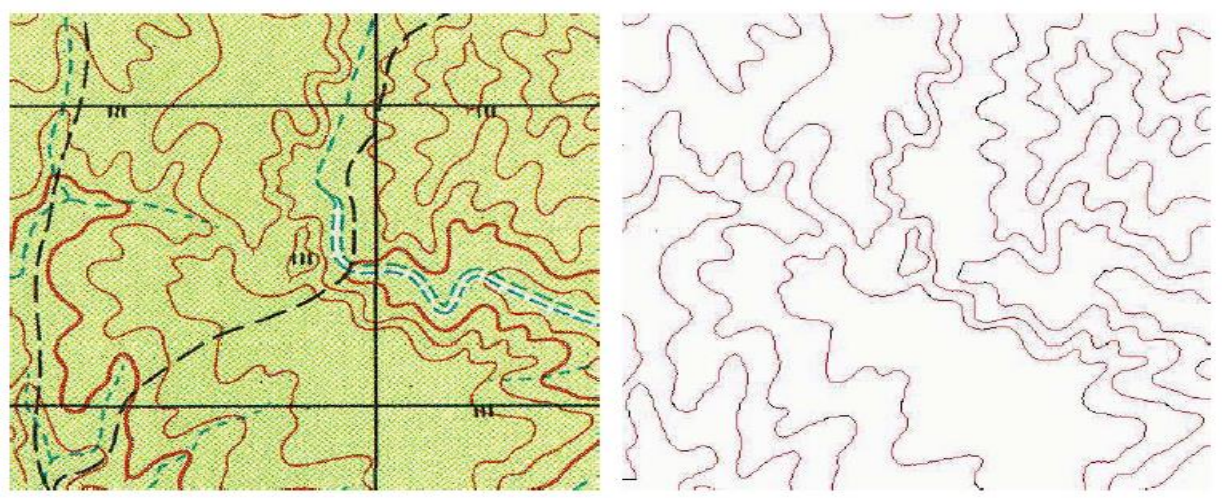

Figure 3 The paper map is scanned and then the contour lines are extracted to some layers

After vectorizing TM25, TM50 and TM100 (paper maps and reproduction originals) in a vector form, an additional activity was the control and modeling of data (Figure
4). That control was used to check the reference data (geodetic points) and implementation the modifications and updates, according to the available reference data sources.

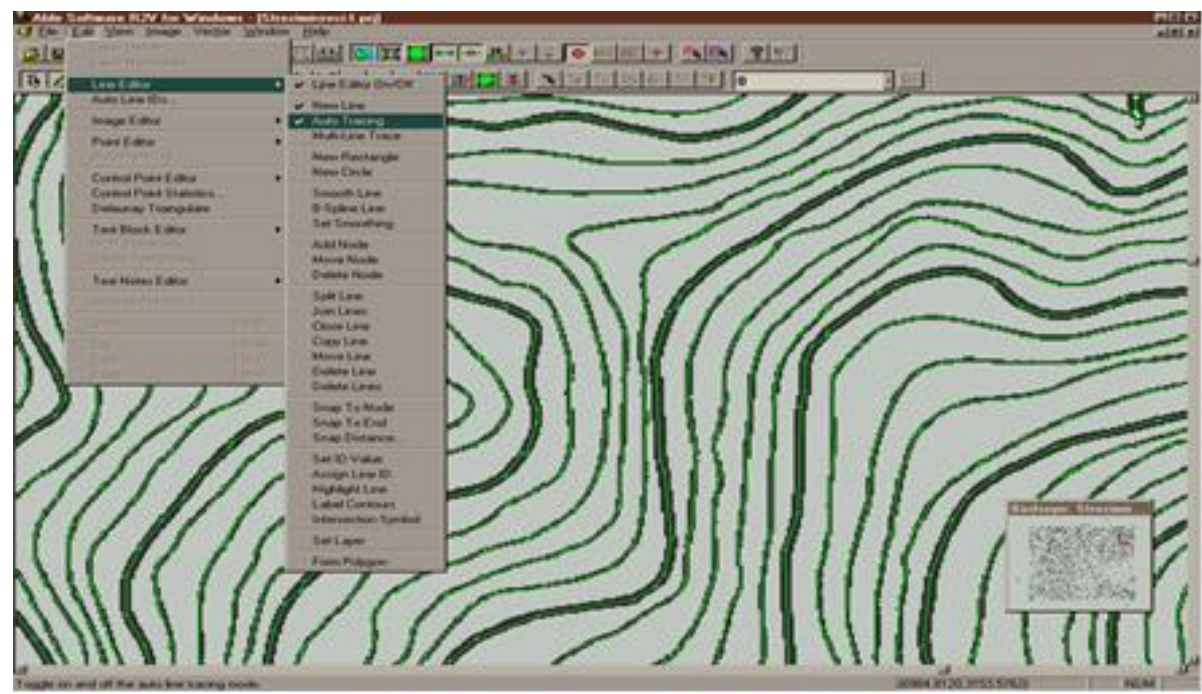

Figure 4 The process of vectorization from raster to vector data

The limiting factors are certainly the original data collection errors. The limits of the contour line errors are given in Table 6 with the positional mean square error in meters. The types of the terrain and slope are also given in the same Table. 
Deformations can be up to 1.5 times higher in the covered field. In the mountainous regions, the number of contour lines is adjusted to the height difference between the top and foot of the mountain.

Table 6 Limits of contour lines errors, types of terrain and the slope

\begin{tabular}{|c|c|c|}
\hline $\begin{array}{c}\text { Flat terrain } \\
0^{0}-2^{0}\end{array}$ & $\begin{array}{c}\text { Hilly terrain } \\
2^{0}-6^{0}\end{array}$ & $\begin{array}{c}\text { Mountainous terrain } \\
>6^{0}\end{array}$ \\
\hline $\pm 3.9 \mathrm{~m}$ & $\pm 5.1 \mathrm{~m}$ & $> \pm 5 \mathrm{~m}$ \\
(depends on the slope)
\end{tabular}

When discussing the quality of data obtained by digitization the existing topographic maps, it should be kept in mind that all the data has already been processed. Specifically, this data was already reviewed, which includes the removal of irregular details on the digitalized content as a result of surface deformation and random errors.

On the other hand, the processing that has been already made using this data carries certain risks. Since this data has been already processed, it is practically impossible to remove all the errors, which were made during that modeling, from the data, because there is usually no information that could be used for reconstructing the original data. Errors, contained in the data obtained by the digitalization of the existing maps, contain both errors of the original data collection and processing (both surveying and mapping errors) and also transformation errors (scanning, georeferencing, vectorization, modeling and processing of data).

For digital models generated from the classic cartographic material, it is usually assumed that the elevation accuracy is from $1 / 4$ to $1 / 5$ of the equidistance of the represented contour lines (Frančula, 2003). Based on the experience and empirical values, achieved for the value of the graphical scribing, the accuracy is usually set to $0.2 \mathrm{~mm}$. In Table 7, the empirical accuracies of the 3D data model created by digitization of cartographic material are presented.

Table 7 The quality of 3D data model obtained by digitization the TM25, TM50 and TM100

\begin{tabular}{|c|c|c|c|}
\hline Scale & Equidistance (m) & $\begin{array}{c}\text { Vertical accuracy } \\
(\mathbf{m})\end{array}$ & $\begin{array}{c}\text { Graphic scribing } \\
\text { accuracy }(\mathbf{m})\end{array}$ \\
\hline $1: 25000$ & 10 & 2,1 & 5 \\
\hline $1: 50000$ & 20 & 3,9 & 10 \\
\hline $1: 100000$ & 20 & 5,1 & 14 \\
\hline
\end{tabular}

\section{DIGITAL TERRAIN MODEL}

Despite that, the vertical system in digital cartography is usually represented in a grid form. In that case, it could be said that accuracy of the digital elevation representation depends directly on the sources and technologies used for measuring the geodata on the density of elevation points (i.e. grid size) and their geometric positions on the terrain slope (Li, et al., 2005).
Specifically, the process of the DTM production consists of the analog - digital conversion (scanning and vectorization) of contour lines, adding heights to contour lines, transforming vector lines into clouds of points and generating the 3D data model.

From an interpretation and topological aspect, there are two basic forms which 
can represent the DTM - regular grid and TIN (Figure 5). The quality of the DTM is defined by the positional accuracy of indi vidual points that are directly measured. Their quantity, with respect to the quality of sample, represents the terrain surface.
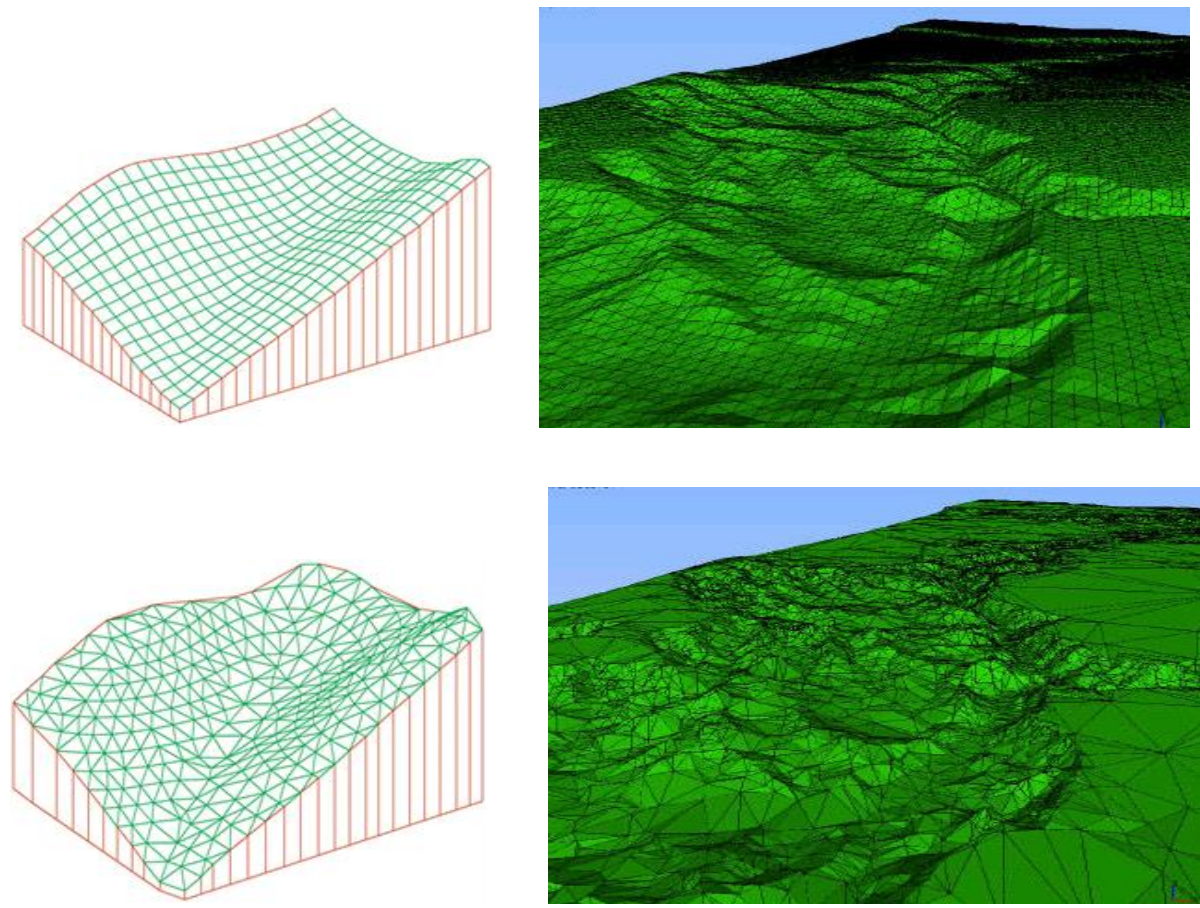

Figure 5 Interpretation of 3D data model in Grid and TIN format

The vertical accuracy of the digital terrain model (DTM), obtained by digiti-zation the contour lines and other features from topographic maps, includes all the sources of errors, both in the process of its conversion into a digital form, and in gene-rating the 3D data model by interpolation ( $\mathrm{Li}$, et al., 2005).

To control the quality of the obtained models (the previously explained method for both procedures), coordinates of the points from the catalog of state points of a trigonometric network, which are located in that area, were used. Thus, there were visual and exact methods for assessing the data quality of the 3D data model (Gorokhovich, Voustianiouk, 2006). For evaluating the accuracy, the equation for standard errors is used:

$$
\sigma_{H}=\sqrt{\frac{\sum\left(z_{i}^{*}-z_{i}\right)^{2}}{n}} ;
$$

where:

$z_{i}^{*}$ - checkpoint height obtained by interpolation;

$z_{i}$ - provided control points height; and

$n$ - number of control points.

The vertical accuracy of the DTM obtained is based on the digitalized contour lines from the topographic maps (reproduction originals) and is shown in Table 8. In this case, beside the grid and triangular irregular network (TIN), the grid model is created by two methods of interpolation and visualization of the elevation surface. One of them is the inverse distance weighed 
$(I D W)$, and the other method is a spline using software ArcGIS - 3D Analyst,
(ESRI, 2010). They are also presented in different resolutions.

Table 8 The quality of DTM obtained on a basis of digitized contour lines of originals TM

\begin{tabular}{|c|c|c|c|c|c|c|c|c|c|c|c|c|c|c|}
\hline \multicolumn{5}{|c|}{ TM25 } & \multicolumn{5}{|c|}{ TM50 } & \multicolumn{5}{|c|}{ TM100 } \\
\hline \multirow{4}{*}{ TIN } & \multicolumn{4}{|c|}{ GRID } & \multirow{4}{*}{ TIN } & \multicolumn{4}{|c|}{ GRID } & \multirow{4}{*}{ TIN } & \multicolumn{4}{|c|}{ GRID } \\
\hline & \multicolumn{2}{|c|}{ IDW } & \multicolumn{2}{|c|}{ Spline } & & \multicolumn{2}{|c|}{ IDW } & \multicolumn{2}{|c|}{ Spline } & & \multicolumn{2}{|c|}{ IDW } & \multicolumn{2}{|c|}{ Spline } \\
\hline & \multicolumn{4}{|c|}{ Resolution - step (m) } & & \multicolumn{4}{|c|}{ Resolution - step (m) } & & \multicolumn{4}{|c|}{ Resolution - step (m) } \\
\hline & 25 & 10 & 25 & 10 & & 50 & 20 & 50 & 20 & & 100 & 40 & 100 & 40 \\
\hline \multicolumn{15}{|c|}{ The mean square error (m) } \\
\hline 2.3 & 2.9 & 2.7 & 1.9 & 1.7 & 4.6 & 5.2 & 5.0 & 3.6 & 3.4 & 7.9 & 8.2 & 7.9 & 6.3 & 6.1 \\
\hline
\end{tabular}

The precision of a grid model is determined by the cell dimensions. A high density grid with points of high accuracy produces an accurately approximated surface, (URL 2). But the TIN model is in the form of triangulated irregularly scattered points and depends on the degree of the surface slope and curvature. For an increased accuracy of surface approximation, the TIN model requires dense points and inclusion thecharacteristic break lines, (URL 2).

\section{CONCLUSION}

This paper presents some ways to obtain the vertical accuracy of data on the digital topographic maps and using a 3D data model obtained on the basis of digitized contour lines of originals topographic maps. Namely, height information is more and more important in the decision making process, monitoring and planning processes in state administration, engineering, mining and other areas of public life. Using digital technologies has significantly increased the geospatial information marketplace, and is still increasing it, both user and producer wise (URL 2).

The vertical accuracy of digital data is in accordance with the data derived from the classic topographic maps, having to meet requirements generally formulated by the national standards, (Gorokhovich, Voustianiouk, 2006). From the mathematical point of view, the reliable DTM must have the surface geometric continuity and possibility of differentiability and smoothness surface at any point. In practice, however, good DTM considers the model that illustrates the terrain topography confidentially and well.

The data quality on topographic maps primarily depends on the chosen scale and method of visualizing the elevation surface. Moreover, the vertical accuracy of content depends on the application methods of interpolation. The analysis of the three different scales (TM25, TM50, TM100) and interpolation methods, i.e. the method of inverse distance weighting and spline, over the same set of spatial data of the selected areas carry out important conclusions. In the interpretation of spatial data continuity and terrain topography, the best results were obtained by spline method and scale TM25. Similar representations are obtained in all scales by the spline method and method of inverse distance weight.

\section{REFERENCES}

[1] Radojčić, S., Borisov, M., Božić, B., 2011. Positional Accuracy of Geographical Information and Recent Standards for its Evaluation, Bulletin of The Serbian Geographical Society, Volume XCI - No. 2, pp. 107-112., Belgrade, Serbia.

[2] Aguilar, F. J., Mills, J. P., Delgado, J., Aguilar, M. A., Negreiros, J. G. and Pérez, J. L., 2010. Modelling Vertical 
Error in Lidar-Derived Digital Elevation Models, ISPRS Journal of Photogrammetry and Remote Sensing 65(1), 103-110.

[3] Environmental Systems Research Institute /ESRI, 2010. Using Arc GIS 3D Analyst, User Guide, Redlands, USA.

[4] Frančula, N., 2003. Digital Cartography, Faculty of Geodesy, Zagreb, Croatia.

[5] Gorokhovich, Y., Voustianiouk, A., 2006. Accuracy Assessment of the processed SRTM-Based Elevation Data by CGIAR Using Field Data from USA and Thailand and its Relation to the Terrain Characteristics, Remote Sensing of Environment, No. 104, pp. 409-415.

[6] Hasegawa, H., Ishiyama, N., 2013. Publication of the Digital Maps (Basic Geospatial Information), Bulletin of The GeoSpatial Information Authority of Japan, Tokio, Japan, pp. 19-24.

[7] Iliffe, J. C; Ziebart, M. K; Turner, J. F; Talbot, A. J; Lessnoff, 2013. Accuracy of Vertical Datum Surfaces in Coastal and Offshore Zones, Survey Review, Vol. 45, No. 331. Bristol, United Kingdom.

[8] ISO, 2013. The International Organization for Standardization, ISO19157: Geographic Information - Quality Principles, Geneva, Switzerland.

[9] Perdue N., 2013. The Vertical Space Problem, Article, Cartographic Perspectives, Journal of the North American Cartographic Information Society, No. 74, pp. 9-28, USA.

[10] Petrović M. V., Zlatanović D., Borisov M., Djurdjevac Ignjatović L., 2016. Concepts of 3D Terrain Modelling and Geomorphometric Analysis in Mining, Mining \& Metallurgy Engineering Bor, No. 3, pp. 1-12.

[11] URL 1: Mining BasinBor - Krivelj http://rtb.rs/rtb-bor-doo/rudnik-bakrabor/rudnik-bakra-veliki-krivelj/

[12] URL 2: Vertical Accuracy Centremaps Live. http:///www.centremapslive.co.uk/page /height_information.asp 